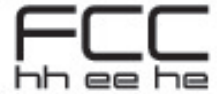

Future Circular Collider

\section{PUBLICATION}

\section{The CERN FCC Conductor Development Program: A Worldwide Effort for the Future Generation of High Field Magnets}

Ballarino, Amalia (CERN) et al.

09 January 2019

The research leading to this document is part of the Future Circular Collider Study on the CERN Document Server at the following URL : 


\title{
The CERN FCC Conductor Development Program: A Worldwide Effort for the Future Generation of High Field Magnets
}

\author{
A. Ballarino, S. C. Hopkins, B. Bordini, D. Richter, D. Tommasini, L. Bottura, M. Benedikt, M. Sugano, T. Ogitsu, \\ S. Kawashima, K. Saito, Y. Fukumoto, H. Sakamoto, H. Shimizu, V. Pantsyrny, I. Abdyukhanov, M. Shlyakov, \\ S. Zernov, F. Buta, C. Senatore, I. Shin, J. Kim, J. Lachmann, A. Leineweber, S. Pfeiffer, T. Baumgartner, \\ M. Eisterer, J. Bernardi, A. Malagoli, V. Braccini, M. Vignolo, M. Putti, and C. Ferdeghini.
}

\begin{abstract}
The study of next generation high energy accelerators based on $16 \mathrm{~T}$ dipoles has emphasized the need for higher performance, cost-effective $\mathrm{Nb}_{3} \mathrm{Sn}$ superconducting wires. A Conductor Development Program aiming to reach a non-copper critical current density $\left(J_{c}\right)$ of $1500 \mathrm{~A} / \mathrm{mm}^{2}$ at $16 \mathrm{~T}$ and $4.2 \mathrm{~K}$ has been launched by CERN, with the involvement of industry and laboratories worldwide. In this article, the targets and strategy of the program are presented, with an overview of the wire layouts and development activities being pursued by each partner, and the latest characterization results are reported. Three of the four participating manufacturers have successfully reached the first stage $J_{c}$ milestone, but a significant advance is still needed to achieve the final target. The next steps are briefly discussed, as the program focuses increasingly on novel alloys and methods to maximize $J_{c}$.
\end{abstract}

Index Terms-Accelerator magnets, niobium-tin, superconducting materials, superconducting filaments and wires.

Manuscript receipt and acceptance dates will be inserted here. (Corresponding author: Simon C. Hopkins.)

A. Ballarino, S. C. Hopkins, B. Bordini, D. Richter, D. Tommasini, M. Benedikt and L. Bottura are with the European Organization for Nuclear Research (CERN), CH-1211 Geneva 23, Switzerland (e-mail: amalia.ballarino@ cern.ch; simon.hopkins@cern.ch; bernardo.bordini@cern.ch; david.richter@cern.ch; davide.tommasini@cern.ch; michael.benedikt@cern.ch; luca.bottura@ cern.ch).

M. Sugano and T. Ogitsu are with the High Energy Accelerator Research Organization, KEK, 1-1 Oho, Tsukuba, Ibaraki 305-0801 Japan.

S. Kawashima, K. Saito, and Y. Fukumoto are with Kobe Steel and Japan Superconductor Technology (JASTEC), Kobe, Japan

H. Sakamoto and H. Shimizu are with Furukawa Electric, Tokyo, Japan

V. Pantsyrny and I. Abdyukhanov are with the A. A. Bochvar HighTechnology Research Institute of Non-Organic Materials, JSC VNIINM, Rogova Street 5a, Moscow 123060, Russia

M. Shlyakov and S. Zernov are with JSC TVEL, 49 Kashirskoe shosse, 115409 Moscow.

F. Buta and C. Senatore are with the University of Geneva, quai ErnestAnsermet 24, 1211 Geneva 4, Switzerland.

I. Shin and J. Kim are with Kiswire Advanced Technology Company, Ltd., Deajeon, South Korea.

J. Lachmann and A. Leineweber are with the Institute of Materials Science, TU Bergakademie Freiberg, Gustav-Zeuner-Str. 5, 09599 Freiberg, Germany.

T. Baumgartner and M. Eisterer are with TU Wien, Atominstitut, Stadionallee 2, 1020 Wien, Austria.

S. Pfeiffer and J. Bernardi are with TU Wien, USTEM, Wiedner Hauptstr. 810, A-1040 Wien

A. Malagoli, V. Braccini, M. Vignolo, and C. Ferdeghini are with CNR-SPIN, Corso Ferdinando Maria Perrone, 24, 16152 Genova, Italy.

M. Putti is with the University of Genova, via Dodecaneso 33, 16146 Genova, Italy.

Color versions of one or more of the figures in this paper are available online at http://ieeexplore.ieee.org.

Digital Object Identifier will be inserted here upon acceptance.

\section{INTRODUCTION}

$\mathbf{H}$ GH Energy Physics has a long history of driving the development of superconducting magnets, and improvements in the design and performance of the superconducting wires used to produce them.

In the context of the High-Luminosity LHC (HL-LHC) Project, a major upgrade program to increase the luminosity of the $\mathrm{LHC}, \mathrm{Nb}_{3} \mathrm{Sn}$ accelerator magnets will be installed for the first time. The requirement for larger-aperture quadrupole magnets, and shorter dipole magnets to allow space for additional collimators, necessitates a significant increase in magnetic field - from a peak field of up to $8.6 \mathrm{~T}$ on the conductor in the LHC, to $11.6 \mathrm{~T}$ for HL-LHC - which cannot be achieved with $\mathrm{Nb}-\mathrm{Ti}$, as used for the LHC. Suitable $\mathrm{Nb}_{3} \mathrm{Sn}$ conductors have been developed using both the Rod Restack Process $\left(\mathrm{RRP}^{\circledR}\right)$ and powder-in-tube technologies, and series production of these wires is advancing towards completion [1].

The proposed Future Circular Collider (FCC) would require another substantial step forward. The FCC Study is developing a number of conceptual designs for a successor particle collider to the LHC, but the baseline is a $100 \mathrm{TeV}$ hadron collider in a $100 \mathrm{~km}$ tunnel with $16 \mathrm{~T}$ dipole magnets. The combination of the high operating magnetic field and the large scale of this facility, for which $\sim 4800$ dipole magnets would be required (including spares), imposes extremely demanding performance and cost targets on the superconducting wire.

The only candidate with proven large-scale industrial production is currently $\mathrm{Nb}_{3} \mathrm{Sn}$ [2], but it is clear that these targets cannot be met by current state-of-the-art $\mathrm{Nb}_{3} \mathrm{Sn}$ wires. In particular, a non-copper critical current density $\left(J_{c}\right)$ of $1500 \mathrm{~A} \mathrm{~mm}^{-2}$ is required at $16 \mathrm{~T}$ and $4.2 \mathrm{~K}$, with a residual resistance ratio (RRR) exceeding 150 and a small effective filament diameter $\left(d_{e f f}\right)$ [2]. CERN has therefore launched a Conductor Development Program to drive the development of a suitable wire in partnership with industry and academia [3].

This article introduces the structure and strategy of the Conductor Development Program, presents a selection of the 
FCC Conductor Development Programme

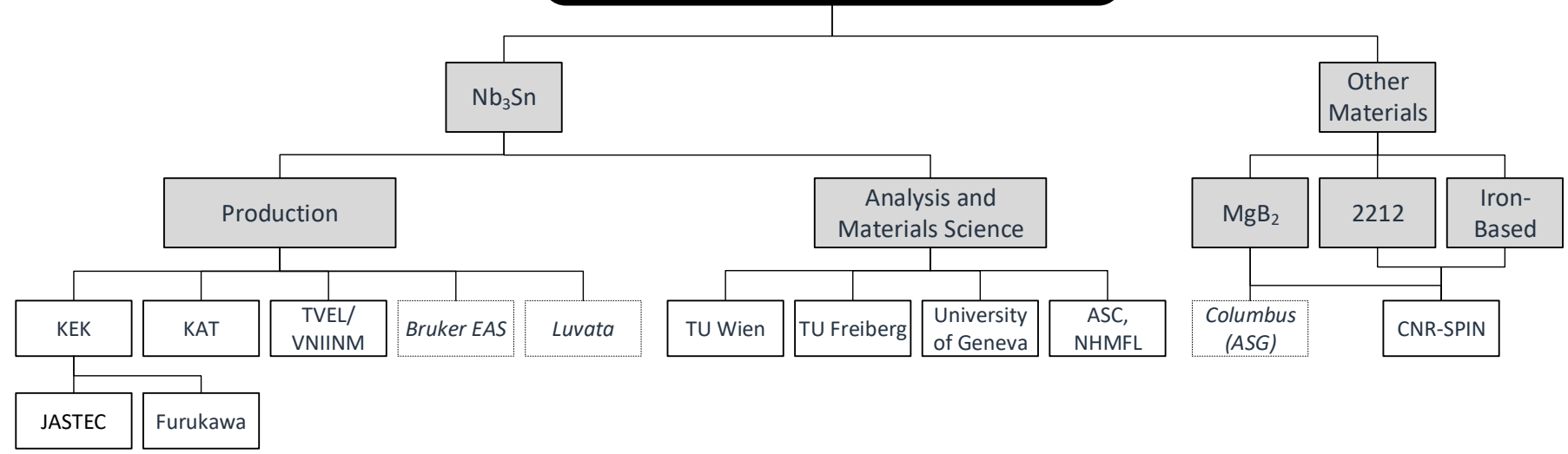

Fig. 1. Schematic of the FCC Conductor Development Programme, showing the activities (shaded boxes) and partners. A dotted outline and italic text indicate pending participants, whose participation is currently being finalised.

wire layouts currently under development, summarizes the progress achieved so far and comments on future prospects.

\section{THE CONDUCTOR DEVELOPMENT PROGRAM}

The Conductor Development Program aims to develop wires meeting the requirements of the superconducting magnets for the FCC, with proven scalability to long-length industrial production, and the potential for cost reduction.

As noted above, the program is centered on $\mathrm{Nb}_{3} \mathrm{Sn}$ wires, for which the target parameters are listed in Table 1 . The fundamental approach is to engage the broadest possible community in this effort. The program therefore includes prototyping and pilot production of a diverse range of wire designs with a worldwide network of industrial partners.

The strategy is to focus on two initial goals (also in Table 1): firstly, supporting industrial partners in achieving reliable production of internal tin $\mathrm{Nb}_{3} \mathrm{Sn}$ wire with a performance comparable to the HL-LHC specification (stage 1), and then prioritizing increases in the high-field critical current performance (stage 2).

At present, industrial wire development projects are in progress with Kiswire Advanced Technology (KAT) in South Korea and TVEL in Russia, and activities with Bruker EAS and Luvata are planned. In addition, Japan Superconductor Technology (JASTEC) and Furukawa Electric are participating in the context of a joint collaborative program with the High Energy Accelerator Research Organization, KEK, Japan.

TABLE I

DEVELOPMENT TARGETS FOR $\mathrm{NB}_{3} \mathrm{SN}$ WIRE

\begin{tabular}{cccc}
\hline \hline Parameter & Final & Stage 1 & Stage 2 \\
\hline Wire diameter $(\mathrm{mm})$ & $0.7-1.1$ & $\sim 1$ & $\sim 1$ \\
$\mathrm{Cu} /$ non-Cu ratio & $\sim 1$ & $\sim 1$ & $\sim 1$ \\
Non-Cu $J_{c}, 16 \mathrm{~T}$ and $4.2 \mathrm{~K}\left(\mathrm{~A} / \mathrm{mm}^{2}\right)$ & $\geq \mathbf{1 5 0 0}$ & $\geq \mathbf{1 0 0 0}$ & $\geq \mathbf{1 5 0 0}$ \\
$\mu_{0} \Delta M$ at $1 \mathrm{~T}$ and $4.2 \mathrm{~K}(\mathrm{mT})$ & $\leq 150$ & - & - \\
$d_{\text {eff }}(\mu \mathrm{m})$ & $\leq \mathbf{2 0}$ & $\leq \mathbf{6 0}$ & $\leq \mathbf{6 0}$ \\
$\mathrm{RRR}$ & $\geq 150$ & $\geq 150$ & $\geq 150$ \\
Unit length $(\mathrm{km})$ & $\geq \mathbf{5}$ & $\geq \mathbf{0 . 1}$ & $\geq \mathbf{0 . 1}$ \\
Price, $16 \mathrm{~T}$ and $4.2 \mathrm{~K}(€ / \mathrm{kA} \mathrm{m})$ & $\leq 5$ & - & - \\
\hline
\end{tabular}

The Japanese program is supported by the universities of Tohoku and Tokai.

This activity is supported by characterization and analysis at CERN and by TU Wien, and more fundamental studies of thermodynamics and diffusion at TU Bergakademie Freiberg, to obtain a more complete understanding and identify opportunities for optimization. In addition, laboratory-scale studies of novel alloys and internal oxidation methods are in progress in the University of Geneva, and with effect from October 2018, the Applied Superconductivity Center of the National High Magnetic Field Laboratory (Florida State University), to identify routes suitable for industrial implementation that might provide a substantial step forward in $J_{c}$.

The program also supports smaller activities seeking a breakthrough in the high-field performance or cost effectiveness of alternative superconducting materials: currently including studies of $\mathrm{MgB}_{2}$, BSCCO 2212 and iron-based superconductors at CNR-SPIN (Genoa, Italy).

The $\mathrm{Nb}_{3} \mathrm{Sn}$ program runs in synchronization with a Magnet Development Program, which aims to prototype, assess and refine the dipole magnet designs developed in the context of the EuroCirCol project. These magnets are designed to achieve the $16 \mathrm{~T}$ field target when suitable wire is available: for the first short model magnets, $\mathrm{Nb}_{3} \mathrm{Sn}$ wire is being procured with comparable $J_{c}$ to the HL-LHC wire, and the conductor program aims to supply higher-performance wire for the next stage of FCC model magnet development.

\section{EXPERIMENTAL METHODS}

For superconducting characterization at CERN, the following samples were prepared from unreacted wire: for critical current $\left(I_{c}\right)$ measurement, a $\sim 1.2 \mathrm{~m}$ length wound on a coated Ti-6Al-4V VAMAS-type barrel; for residual resistivity ratio (RRR), a straight length of $\sim 150 \mathrm{~mm}$; and for magnetization measurements, either a straight sample $\sim 6 \mathrm{~mm}$ in length, or a mini-coil wound on a $5 \mathrm{~mm}$ thread to obtain a total length of $\sim 125 \mathrm{~mm}$. The manufacturer's recommended heat treatment was then performed under vacuum on this set of samples. 
Transport critical current $\left(I_{c}\right)$ measurements were performed in liquid helium $(4.3 \mathrm{~K})$ at $12-15 \mathrm{~T}$, using an electric field criterion of $0.1 \mu \mathrm{V} / \mathrm{cm}$. Magnetization was measured using a vibrating sample magnetometer (VSM; Cryogenic, UK) at $4.2 \mathrm{~K}$ with a field range of $\pm 10 \mathrm{~T}$, from which the effective filament diameter $\left(d_{\text {eff }}\right)$ was determined by comparison with the scaled transport $J_{e}$ [4]. RRR was calculated from four-point resistance measurements at room temperature and $\sim 20 \mathrm{~K}$.

For scanning electron microscopy (SEM), wire samples were cut with a diamond wire saw, placed in a brass support and hot mounted in a conductive phenolic resin. For optical microscopy, cold mounting was used. The mounted specimens were prepared for examination with a sequence of grinding (SiC paper) and polishing (diamond suspension) steps down to $1 \mu \mathrm{m}$ or smaller. SEM was performed using a Zeiss Sigma field emission SEM, typically using an accelerating voltage of $10 \mathrm{kV}$, and energy-dispersive x-ray spectroscopy (EDX) was used for compositional analysis.

In some cases, as indicated in the text, measurements are contributed by the manufacturer: these use identical heat treatments and comparable methods, but exact procedures may differ.

\section{PRototype $\mathrm{NB}_{3} \mathrm{SN}$ WiReS}

In this section, the designs and performance of a selection of wires produced by industrial partners in the program are summarized. Additional characterization based on image analysis is reported in [5].

\section{A. TVEL/Bochvar Institute (VNIINM)}

During a project running from 2016-2017, the Bochvar Institute (VNIINM) developed and prototyped several designs of internal tin $\mathrm{Nb}_{3} \mathrm{Sn}$ wire, and performed pilot production at Chepetsky Mechanical Plant (ChMP) to demonstrate the feasibility of long-length manufacturing. The project included de-

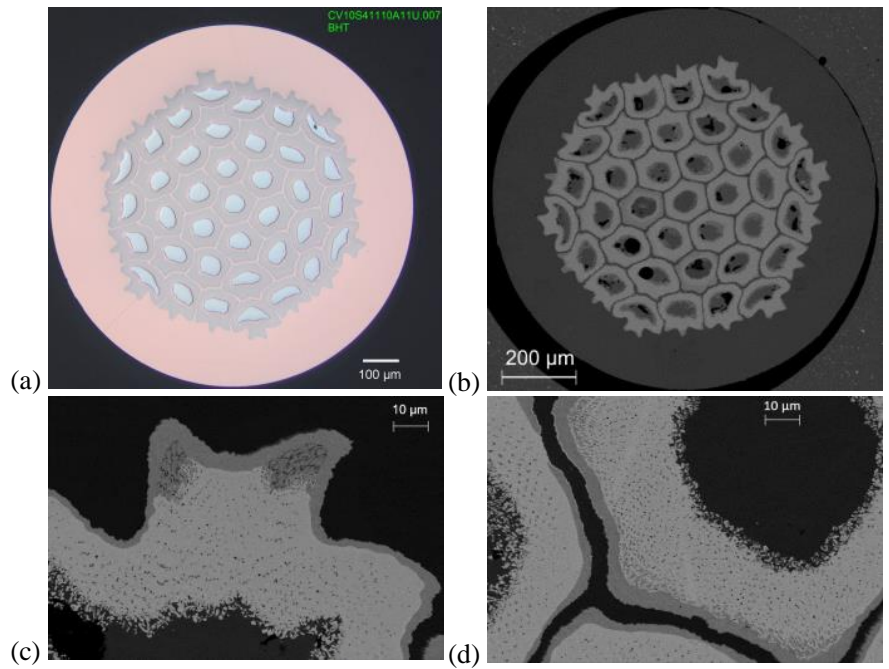

Fig. 2. Micrographs of the distributed barrier wire developed and produced by TVEL in late 2017. (a) Optical micrograph of an unreacted wire; (b) backscattered electron micrograph of a reacted sample; and back-scattered electron micrographs of sub-elements showing incomplete reaction (c) at the periphery of a sub-element, and (d) particularly in distorted sub-elements.
TABLE II

CHARACTERISTICS OF TVEL DISTRIBUTED BARRIER WIRES

\begin{tabular}{|c|c|c|c|}
\hline Parameter & Specification & Achieved $^{\mathrm{a}}$ & $\begin{array}{l}\text { Meas- } \\
\text { ured }\end{array}$ \\
\hline Wire diameter $(\mathrm{mm})^{\mathrm{b}}$ & $1.000 \pm 0.003$ & $1.002-1.003$ & CERN \\
\hline $\mathrm{Cu} /$ non- $\mathrm{Cu}$ ratio & $1.2 \pm 0.2$ & $1.18-1.34$ & Both \\
\hline $\begin{array}{c}\text { Non-Cu } J_{c}, 12 \mathrm{~T} \text { and } \\
4.3 \mathrm{~K}\left(\mathrm{~A} / \mathrm{mm}^{2}\right)\end{array}$ & $\begin{array}{l}2450 \pm 5 \% \\
(4.2 \mathrm{~K})\end{array}$ & $2329-2720$ & CERN \\
\hline $\begin{array}{l}\text { Best scaled } J_{c}, 16 \mathrm{~T} \text { and } \\
4.2 \mathrm{~K}\left(\mathrm{~A} / \mathrm{mm}^{2}\right)\end{array}$ & N/A & 1140 & CERN \\
\hline RRR & $\geq 150$ & $\begin{array}{c}\text { 199-276 } \\
\text { (mean: 249) }\end{array}$ & CERN \\
\hline $\begin{array}{c}\text { Geometrical sub-element } \\
\text { diameter }(\mu \mathrm{m})^{\mathrm{c}}\end{array}$ & $\leq 120$ & $\begin{array}{c}107-112 \\
\text { (mean: } 110)\end{array}$ & CERN \\
\hline$d_{e f f}(\mu \mathrm{m})^{\mathrm{d}}$ & $\leq 120$ & $134-144$ & CERN \\
\hline Unit length (m) & $\geq 200$ & $542-1435$ & TVEL \\
\hline
\end{tabular}

${ }^{a}$ Unless otherwise specified, ranges represent the minimum and maximum values measured across the 11 piece lengths supplied.

${ }^{\mathrm{b}}$ Measured by laser micrometer for two samples.

'Diameter of circle of equal area to the sub-element, as determined by image analysis: the reported range is for all sub-elements in a single wire sample.

${ }^{\mathrm{d}}$ Measured for one mini-coil sample each from two piece lengths.

signs with common (single) and with distributed diffusion barriers, of $\mathrm{Ta}, \mathrm{Nb}$ and $\mathrm{Ta} / \mathrm{Nb}$. In addition, a sub-element layout with $\mathrm{Cu}$ separators was prototyped in order to reduce $d_{e f f}$.

A 37 sub-element layout with distributed niobium barriers was selected for trial production (Fig. 2), and $12 \mathrm{~km}$ of $1 \mathrm{~mm}$ diameter wire was successfully produced and delivered to CERN in piece lengths averaging more than $1 \mathrm{~km}$. The wire was designed for a higher $\mathrm{Cu} /$ non- $\mathrm{Cu}$ ratio, 1.2 , than the present FCC target.

After heat treatment $\left(100 \mathrm{~h}\right.$ at $370{ }^{\circ} \mathrm{C}, 40 \mathrm{~h}$ at $\left.665^{\circ} \mathrm{C}\right)$, the resulting characteristics are tabulated in Table II. All results are consistent with the intended specification, except $d_{\text {eff, }}$, which exceeds the geometrical sub-element size: this may be due to the non-uniform geometry of peripheral sub-elements (Fig. 2(c)), which is analyzed in more detail in [5]. The RRR is very high and consistent (the minimum value of 199 is an outlier). The measured critical current for all piece lengths is summarized in Fig. 3.

Scaling the non-copper $J_{c}$ to the FCC reference conditions (an applied field at $16 \mathrm{~T}$ and $4.2 \mathrm{~K}$ ) gives a value of $1140 \mathrm{~A} \mathrm{~mm}^{-2}$ for the best sample. This is a promising result, and there is evidence that this can be further improved through

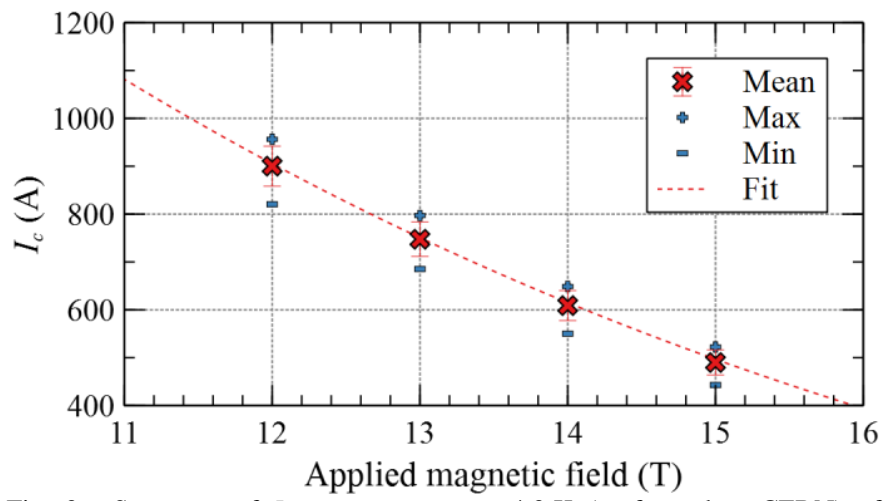

Fig. 3. Summary of $I_{c}$ measurements at $4.3 \mathrm{~K}$ (performed at CERN) of TVEL trial wires. Error bars represent the standard deviation of measured values between piece length; the minimum and maximum values are also shown, along with an extrapolated fit of the mean values. 
optimization of the heat treatment and deformation processing: residual niobium regions suggest incomplete reaction at the periphery of some sub-elements (Fig. 2(d)), and especially in distorted peripheral sub-elements (Fig. 2(c)) [5]. A detailed microstructural study of a selection of wires from TVEL is now in progress in TU Wien to identify the most promising directions for future development, and CERN and TVEL have recently signed a new agreement (September 2018) to continue this development for a further two years.

\section{B. Kiswire Advanced Technology (KAT)}

KAT began its four-year wire development project for the FCC Study in March 2017, and is pursuing three main types of common-barrier wire design, differing primarily in the distribution of tin and the niobium filament size. The detailed layout of each design is evolving through a series of trials, the most recent of which is summarized in Table III, supported in parallel by engineering tests of specific technologies and design approaches.

The most promising performance has so far been obtained with Type I designs (see table IV). For the best of the first trial wires, a $J_{c}$ exceeding $1000 \mathrm{~A} \mathrm{~mm}^{-2}$ at $16 \mathrm{~T}$ and $4.2 \mathrm{~K}$, and a high RRR 200 was reported early in 2018 [6]. Electron microscopy analysis (Fig. 4) identified several opportunities for improvement. The residual tin content of the matrix was high (Fig. 4(c)), especially for the variant labelled design 3, and the radial profile was very uniform, perhaps suggesting that the long heat treatment (final plateaus of $200 \mathrm{~h}$ and $250 \mathrm{~h}$ at $650{ }^{\circ} \mathrm{C}$ for designs 2 and 3 respectively) could be reduced. Some bridging between sub-elements was also apparent, consistent with a larger $d_{e f f}$ than the nominal sub-element size determined from VSM data (Table III). The barrier thickness was also found to be as low as $3 \mu \mathrm{m}$ in some locations, suggesting caution needed in reducing the nominal thickness.

$$
\text { TABLE III }
$$

CHARACTERISTICS OF KAT WIRE DESIGNS: CURRENT TRIALS

\begin{tabular}{|c|c|c|c|}
\hline Parameter & Type I & Type II & Type III \\
\hline $\begin{array}{l}\text { Main } \mathrm{Sn}-\mathrm{Ti} \\
\text { source }\end{array}$ & $\begin{array}{l}\text { Between sub- } \\
\text { elements }\end{array}$ & $\begin{array}{l}\text { Center of sub- } \\
\text { elements }\end{array}$ & $\begin{array}{l}\text { Distributed in } \\
\text { sub-elements }\end{array}$ \\
\hline $\begin{array}{l}\text { Diffusion bar- } \\
\text { riers }\end{array}$ & $\begin{array}{l}\text { 1. Common, } \mathrm{Ta} \\
\text { 2. Core, } \mathrm{Nb}\end{array}$ & Common, Ta & Common, Ta \\
\hline $\begin{array}{l}\text { Diameter } \\
(\mathrm{mm})\end{array}$ & 1.0 & 0.7 & 1.3 \\
\hline $\mathrm{Cu} / \mathrm{non}-\mathrm{Cu}$ & 0.855 & 1.077 & $\sim 1$ \\
\hline $\begin{array}{l}\text { Number of } \\
\text { sub-elements }\end{array}$ & $\begin{array}{c}192(132 \mathrm{Nb}, 60 \\
\text { Sn-Ti) }\end{array}$ & 61 & 91 \\
\hline $\begin{array}{l}\text { Filament size } \\
(\mu \mathrm{m})\end{array}$ & 2.8 & 1.4 & 7.5 \\
\hline $\begin{array}{l}\text { Sub-element } \\
\text { design }\end{array}$ & & & \\
\hline $\begin{array}{l}\text { Cross-section } \\
\text { (optical mi- } \\
\text { crograph) }\end{array}$ & & & \\
\hline
\end{tabular}

TABLE IV

PERFORMANCE OF KAT TYPE I DESIGNS

\begin{tabular}{ccc}
\hline \hline Parameter & End 2017 & Summer 2018 \\
\hline Number of modules & $91(60 \mathrm{Nb}, 31 \mathrm{Sn}-\mathrm{Ti})$ & $192(132 \mathrm{Nb}, 60 \mathrm{Sn}-\mathrm{Ti})$ \\
Diameter $(\mathrm{mm})$ & 0.700 & 1.004 \\
$\mathrm{Cu} / \mathrm{non}-\mathrm{Cu}$ & 0.928 & 0.855 \\
Non-Cu $J_{c}, 16 \mathrm{~T}$ & 1019 & 995 \\
and $4.2 \mathrm{~K}\left(\mathrm{~A} \mathrm{~mm} \mathrm{~mm}^{-2}\right)$ & & 186 \\
RRR & 196 & 43.1 \\
Nominal sub- & 44.2 & 69.2 \\
element size $(\mu \mathrm{m})$ & 103.4 & Pending \\
$d_{\text {eff }}$ at $1 \mathrm{~T}(\mu \mathrm{m})$ & 74 & \\
$d_{e f f}(\mu \mathrm{m})^{\mathrm{a}}$ & &
\end{tabular}

Measurements performed by KAT unless otherwise stated

${ }^{a}$ Measurement performed by CERN; calculated for 8-10 T range
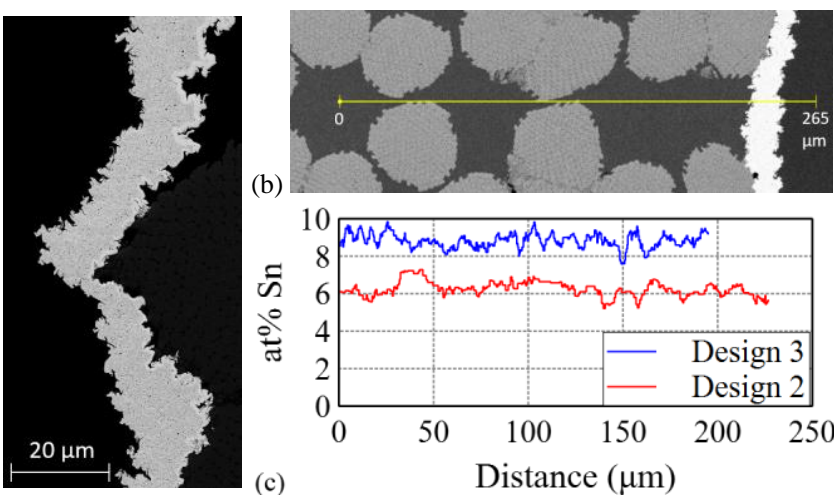

Fig. 4. Electron microscopy of the first trial type I wires produced by KAT. (a) Backscattered electron image of the diffusion barrier (both matrix and filaments are black) for a wire of design 2; (b) backscattered electron micrograph showing bridging between some sub-elements of a wire of design 2, with an overlay indicating the location of an EDX line scan; and (c) radial Sn composition profiles measured by EDX in the $\mathrm{Cu}-\mathrm{Sn}$ matrix alone.

In the most recent trials, the barrier thickness has been successfully reduced from $20 \mu \mathrm{m}$ to $10 \mu \mathrm{m}$ in a $1 \mathrm{~mm}$ diameter wire whilst retaining the high RRR; and both the $\mathrm{Nb}$ filament diameter and the sub-element size have been decreased (when scaled according to the wire diameter). Importantly, the $d_{\text {eff }}$ has also decreased, with a reduction in flux jumps at low field, whilst preserving comparable $J_{c}$. Heat treatment optimization, and an analysis of the distribution of $\mathrm{Sn}$ and $\mathrm{Ti}$, is in progress to further improve the $J_{c}$.

Further trials are in progress to improve the deformation processing of type III wires with an increased number of subelements, further decrease $d_{\text {eff }}$ in types I and III, and increase $J_{c}$ by optimizing the component fractions and degree of reaction. After analysis of these trials, production of three R\&D billets (each of $2 \mathrm{~km}$ ) is planned for the start of 2019, when the resulting material will be characterized at CERN. The final stage of the project will include the supply of $20 \mathrm{~km}$ of a chosen design for cabling trials at CERN.

\section{JASTEC}

JASTEC, in the context of the Japanese program coordinated by KEK, is developing a series of distributed tin (DT) wires [7]. This common-barrier design contains tin islands distributed between the niobium sub-elements. This design has been 
TABLE V

CHARACTERISTICS OF SELECTED JASTEC DisTRIBUTED TIN DESIGNS

\begin{tabular}{cccc}
\hline \hline Parameter & Trial 1 & Trial 3: 1 & Trial 3: 2 \\
\hline Wire diameter $(\mathrm{mm})$ & $0.6-1$ & 0.8 & 0.8 \\
Cu/non-Cu ratio (nominal) & $0.34 \pm 0.05$ & $1.0 \pm 0.2$ & $1.0 \pm 0.2$ \\
Number of sub-elements & $84 \mathrm{Nb}$, & $139 \mathrm{Nb}$, & $139 \mathrm{Nb}$, \\
Non-Cu $J_{c}, 16 \mathrm{~T}$ and $4.3 \mathrm{~K}$ & $37 \mathrm{Sn}-\mathrm{Ti}$ & $72 \mathrm{Sn}-\mathrm{Ti}$ & $72 \mathrm{Sn}-\mathrm{Ti}$ \\
$\left(\mathrm{A} / \mathrm{mm}^{2}\right)^{\mathrm{a}}$ & 952 & 1036 & 1090 \\
$\mathrm{RRR}^{\mathrm{b}}$ & 135 & & \\
$d_{e f f}(\mu \mathrm{m})^{\mathrm{b}}$ & 267 & 54.5 & 55.0
\end{tabular}

${ }^{a}$ Measured at JASTEC (trial 1 at $0.75 \mathrm{~mm}$ diameter); trial 3 pending verification at CERN

${ }^{\mathrm{b}}$ Measured at CERN; trial 1 at $0.7 \mathrm{~mm}$ diameter

developed through three trials, the third of which was recently completed, and a fourth is about to begin (see Table V).

The cross-section of the trial 1 wire design, before and after reaction, is presented in Fig. 5. This wire was produced with very low $\mathrm{Cu}$ fraction, in an effort to maximize $J_{e}$, which had an impact on stability; but a promising $J_{c}$ of $950 \mathrm{~A} \mathrm{~mm}^{-2}$ at $16 \mathrm{~T}$ and $4.3 \mathrm{~K}$ was measured by the manufacturer, and was consistent with scaled measurements at CERN.

At small wire diameters $(0.6-0.7 \mathrm{~mm})$, extensive bridging between sub-elements is apparent as shown in Fig. 5(b), and resulted in a very large $d_{\text {eff }}($ Table $\mathrm{V})$. The radial profiles of residual tin content measured near the centers of the original tin cores (Fig. 6) are similar for wires 0.6 and $0.7 \mathrm{~mm}$ diameter. The majority of the niobium sub-elements are well reacted, and the average residual tin content is low, suggesting an appropriate niobium fraction; but the decrease in concentration
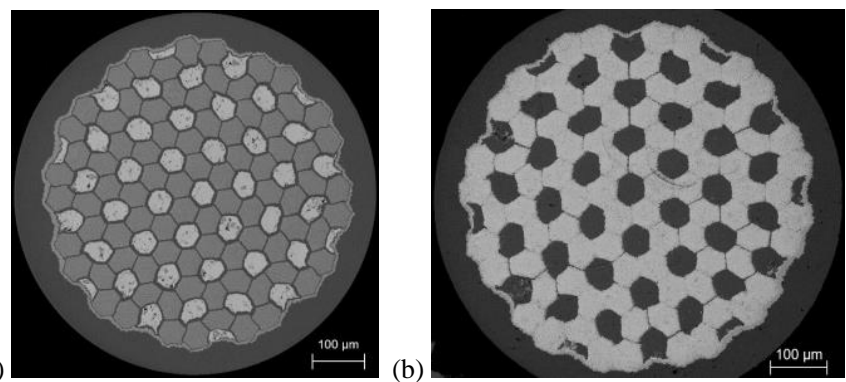

Fig. 5. Backscattered electron images of JASTEC's first trial DT wire at $0.7 \mathrm{~mm}$ diameter (a) before and (b) after reaction.

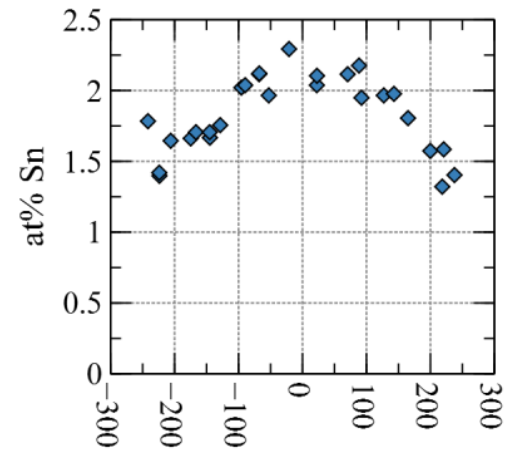

(a) Distance $(\mu \mathrm{m})$

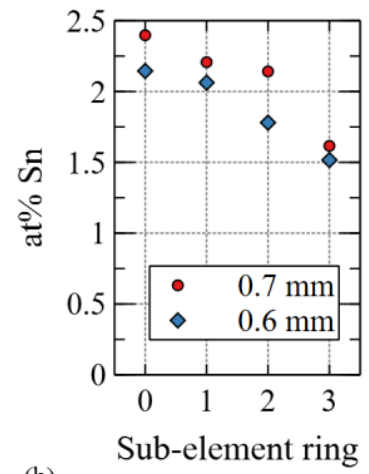

(b)
Fig. 6. Radial profiles of residual tin content in the matrix of reacted JASTEC first trial wires, from EDX spectroscopy: (a) all measured points as a function of radial position for a $0.6 \mathrm{~mm}$ diameter wire, and (b) a comparison of the profiles for 0.6 and $0.7 \mathrm{~mm}$ diameter wires, averaged by the subelement ring number (increasing away from the centre). towards the periphery is correlated with locally incomplete reaction, demonstrating some potential for optimization of the tin distribution. This topic is analyzed in detail in [5].

The design for the third trial addressed these issues with a reduction in sub-element and filament sizes. Magnetization measurements confirmed that $d_{\text {eff }}$ (at $0.8 \mathrm{~mm}$ ) was successfully reduced to $\sim 55 \mu \mathrm{m}$. Two variants were produced with reduced Ti concentration: the $J_{c}$ measured at $16 \mathrm{~T}$ at JASTEC was $\sim 5 \%$ higher for the lowest $\mathrm{Ti}$ content, but considering the modest difference, this conclusion will be verified following comparative measurements at KEK and CERN. The fourth trial has two aims: to increase the $\mathrm{Nb}$ (and hence $\mathrm{Nb}_{3} \mathrm{Sn}$ ) fraction, and to complete the optimization of Ti addition and deformation behavior. Results are expected early in 2019, after which a wire design will be selected for $5 \mathrm{~km}$ pilot production.

\section{Furukawa}

Furukawa is also participating in the joint CERN-KEK Japanese program. Furukawa is an established manufacturer of bronze route $\mathrm{Nb}_{3} \mathrm{Sn}$, e.g. for ITER, and is now developing internal tin wires of two types: a niobium tube design and a distributed tin layout conceptually similar to the one developed by JASTEC and KAT. In the current program, Furukawa is prioritizing the $\mathrm{Nb}$ tube design. Four trials have been performed to date, advancing from an initial 48-filament layout to an 85-filament geometry as shown in Fig. 7.

\section{E. Summary of Progress}

Industrial $\mathrm{Nb}_{3} \mathrm{Sn}$ wire development is progressing well, with four active and engaged manufacturers producing several trial wires per year. In all cases, progress towards the FCC development targets (Table I) has been achieved between successive trials: either an increase in $J_{c}$ or a decrease in $d_{e f f}$.

The $J_{c}$ results are summarised in Fig. 8, with values for the wires procured for HL-LHC for comparison. Three manufacturers have successfully achieved the stage $1 J_{c}$ target (Table 1) comparable to the HL-LHC specification (but it should be noted that $\mathrm{Cu} /$ non-Cu ratio, $d_{\text {eff }}$ and diameter differ): this is approaching a suitable level for FCC cabling and magnet trials, and provides a good baseline for further development.

Stage 2 of the program, targeting $1500 \mathrm{~A} \mathrm{~mm}^{-2}$ at $16 \mathrm{~T}$ and $4.2 \mathrm{~K}$, will still require a major step forward beyond incremental improvements; and novel approaches are therefore a growing focus for the next two years of the program. Work in this direction is currently driven by laboratory studies (section V), and will be enhanced by new partners in the coming months. (a)

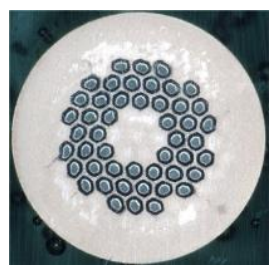

(b)

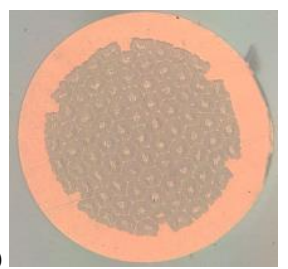

Fig. 7. Optical micrographs of Furukawa tube type wires with (a) 48 and (b) 85 filaments. 


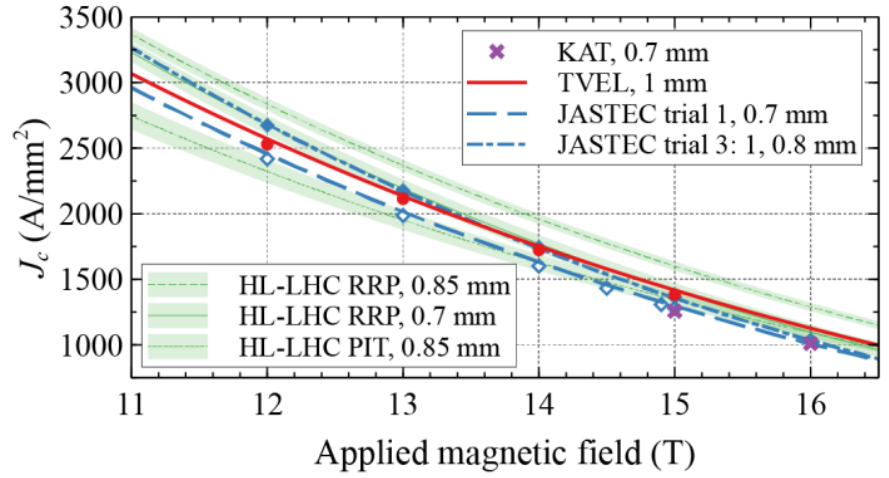

Fig. 8. The $J_{c}(B)$ performance achieved by manufacturers in the Conductor Development Program, compared to the average performance of HL-LHC wires (pale green bands represent the standard deviation). Plotted points are from measurements at CERN and by manufacturers at 4.2-4.3 K: an extrapolated fit is presented (scaled to $4.22 \mathrm{~K}$ ) where sufficient data are available.

\section{V. $\mathrm{NB}_{3} \mathrm{SN}$ LABORATORY STUDIES}

\section{A. Analysis of Tin Gradients and Non-Uniformity in State of the Art Wires (TU Wien)}

TU Wien's participation in the conductor development program explores the correlation between microstructure, local superconducting properties and the macroscopic performance of $\mathrm{Nb}_{3} \mathrm{Sn}$ superconducting wires, and is a collaboration between USTEM (electron microscopy) and the Atominstitut (superconducting properties and irradiation). The work is performed on state-of-the-art commercial $\mathrm{Nb}_{3} \mathrm{Sn}$ wires and on prototype wires produced in this program and elsewhere.

As a result of the diffusion reaction in which $\mathrm{Nb}_{3} \mathrm{Sn}$ is formed, the sub-elements in a wire always exhibit Sn concentration gradients, which influence the wire performance due to the strong dependence of the intrinsic properties on stoichiometry. The spatial variation of the $\mathrm{Sn}$ content within subelements of different wires has been examined by EDX. Fig. 9(a) shows typical results obtained from a Ti-alloyed RRP wire. The Sn content data were averaged over several subelements, and the fitted profile was used as input for the simu-

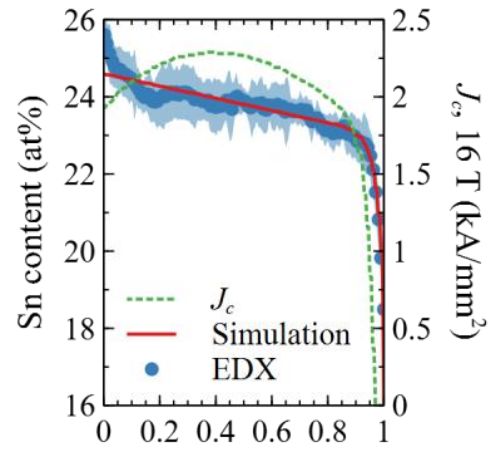

(a)

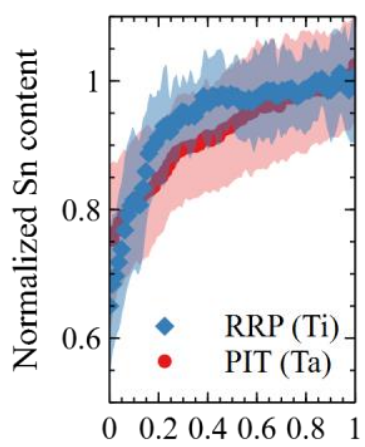

(b) Relative position
Fig. 9. (a) Tin concentration variation across sub-elements in a Ti-alloyed RRP wire measured by EDX (blue dots), the fit (red line) used for simulation of $J_{c}$, and the calculated $J_{c}$ profile (dotted green line; $4.2 \mathrm{~K}, 16 \mathrm{~T}$ ). (b) Normalized tin concentration gradients measured by TEM EDX within the grains of a Ta-alloyed PIT wire and a Ti-alloyed RRP wire. In both cases, the relative position is measured outwards from the centre (0) to the barrier/boundary (1); and pale bands around the EDX values represent the standard deviation. lation code described in [8] to calculate the $J_{c}$ distribution at $4.2 \mathrm{~K}$ and $16 \mathrm{~T}$ within the sub-elements (a grain size of $100 \mathrm{~nm}$ is assumed). As shown in Fig. 9(a), the gradient in stoichiometry leads to a significant variation in $J_{c}$.

Reports of a discrepancy between the $T_{c}$ distributions of $\mathrm{Nb}_{3} \mathrm{Sn}$ wires obtained from calorimetry and magnetometry [9] led to the conjecture that intra-granular Sn concentration gradients must also exist. This has been confirmed by transmission electron microscope (TEM) EDX analysis. Results obtained from two different wire types, averaged over several grains, are shown in Fig. 9(b), in which the Sn content is normalized to its maximum value (at the grain boundary). It is noteworthy that the grains of the Ta-alloyed PIT wire exhibit an almost linear variation of the Sn content, whereas a sharp drop near the center was found in grains of the Ti-alloyed RRP wire. The effects of such intra-granular gradients on the performance of $\mathrm{Nb}_{3} \mathrm{Sn}$ wires are not currently known.

\section{B. Thermodynamics and Phase Transformations in the $\mathrm{Cu}$ - $\mathrm{Nb}-\mathrm{Sn}$ System (TU Bergakademie Freiberg)}

Despite decades of research on growing $\mathrm{Nb}_{3} \mathrm{Sn}$ in $\mathrm{Cu}-\mathrm{Nb}-$ $\mathrm{Sn}$ composite wires (often with the addition of $\mathrm{Ti}$ or $\mathrm{Ta}$ ), knowledge of the thermodynamics of this system is incomplete. This is exemplified by the observation of the ternary phase nausite $\left(\mathrm{Nb}_{0.75} \mathrm{Cu}_{0.25} \mathrm{Sn}_{2}\right)$ [10], which is not present in the evaluated phase diagram. TU Bergakademie Freiberg is contributing to the FCC Study with a detailed investigation of phase equilibria in the $\mathrm{Cu}-\mathrm{Nb}-\mathrm{Sn}$ system, with particular emphasis on the temperature range of relevance to superconducting wires. Analysis of thermodynamics and diffusioncontrolled phase transformations will provide information for optimization and modelling efforts [5]. This work will be extended to consider $\mathrm{Ti}$ additions, and the influence of oxygen and selected oxides, to support the development of practical high-field conductors and novel internal oxidation methods.

Investigations have so far been performed on $\mathrm{Cu}_{6} \mathrm{Sn}_{5}-\mathrm{Nb}$ diffusion couples prepared by pre-reaction of dual $\mathrm{Cu}-\mathrm{Sn}$ layers electroplated on a $\mathrm{Nb}$ substrate. Heat treatment of these couples at different temperatures provides information of the phases of the $\mathrm{Cu}-\mathrm{Nb}-\mathrm{Sn}$ system in equilibrium as a function

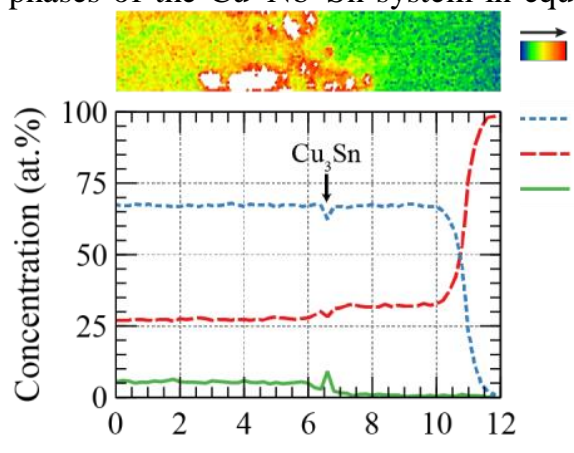

(a) Position $(\mu \mathrm{m})$

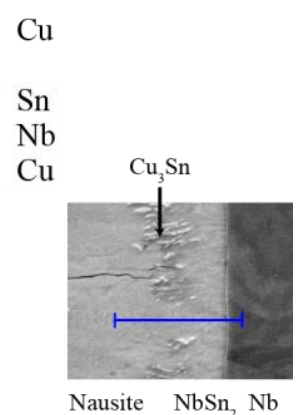

(b)
Fig. 10. Results of EDX measurements on a $\mathrm{Cu}_{6} \mathrm{Sn}_{5}-\mathrm{Nb}$ diffusion couple after heat treatment at $500{ }^{\circ} \mathrm{C}$, leading to development of a layered nausite/ $\mathrm{NbSn}_{2} / \mathrm{Nb}$ system [11]. (a) EDX line scan, and (top) a 2D EDX map showing the distribution of copper, measured in the direction shown in (b), a backscattered electron micrograph. Nausite is clearly distinguished from $\mathrm{NbSn}_{2}$ by its higher copper concentration; local peaks in copper content (shown white in the EDX map) correspond to $\mathrm{Cu}_{3} \mathrm{Sn}$ inclusions. 
of temperature. Fig. 10 shows part of the microstructure which developed after annealing at $500{ }^{\circ} \mathrm{C}$. $\mathrm{Cu}_{6} \mathrm{Sn}_{5}$ has been consumed during the heat treatment, resulting in a nausite/ $\mathrm{NbSn}_{2}$ double layer on the thick $\mathrm{Nb}$ substrate. The EDX profile clearly shows the higher $\mathrm{Cu}$ content in nausite and the step in $\mathrm{Cu} / \mathrm{Nb}$ content at the nausite/ $\mathrm{NbSn}_{2}$ phase boundary, emphasizing the distinctness of the these two phases at $500{ }^{\circ} \mathrm{C}$ [11].

\section{Internal Oxidation Methods for Enhancement of Critical Current Density in $\mathrm{Nb}_{3} \mathrm{Sn}$ Wires (University of Geneva)}

Internal oxidation methods have recently received renewed attention as a promising approach for enhancing the $J_{c}$ of $\mathrm{Nb}_{3} \mathrm{Sn}$ wires. Typically, a $\mathrm{Nb}-\mathrm{Zr}$ alloy replaces pure $\mathrm{Nb}$, and $\mathrm{SnO}_{2}$ is added, such that $\mathrm{ZrO}_{2}$ precipitates are formed during heat treatment [12]. These precipitates can enhance $J_{c}$ by grain refinement of $\mathrm{Nb}_{3} \mathrm{Sn}$ [12][13] or by acting as artificial pinning centers (APCs). Combined $\mathrm{Zr}$ and $\mathrm{O}$ additions had been studied many years earlier [13][14]; recent work has demonstrated the potential for compatibility with PIT and internal tin wire designs [12], but implementation in high- $J_{e}$, high $B_{c 2}$ wires with ternary additions to $\mathrm{Nb}_{3} \mathrm{Sn}$ remains work in progress.

Within the FCC program, a study in the University of Geneva (2017-2018) is investigating internal oxidation of $\mathrm{Zr}$ and other elements in $(\mathrm{Nb}, \mathrm{X})_{3} \mathrm{Sn}$ wires, and the effects on grain size and superconducting properties [15], using a monofila-
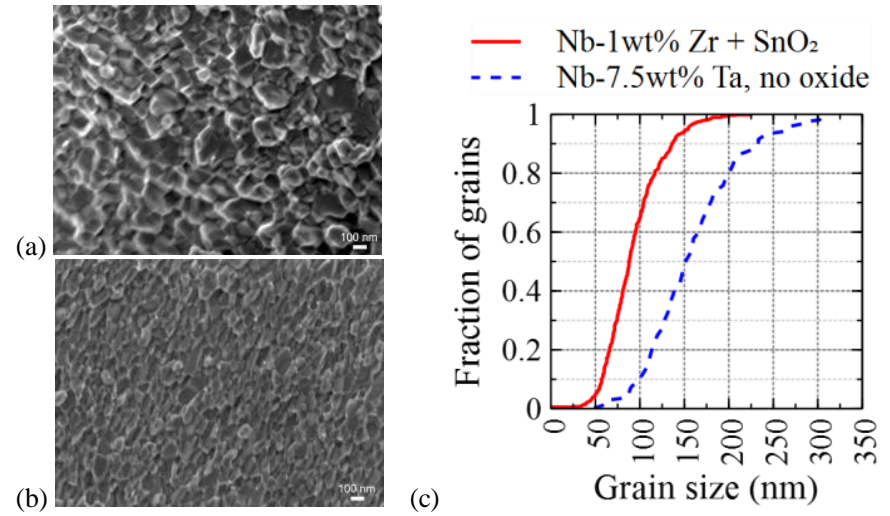

(c)

Grain size (nm)

Fig. 11. Comparison of grain size distribution in a sample with internal oxidation $\left(\mathrm{Nb}-1 \mathrm{wt} \% \mathrm{Zr}\right.$ with $\left.\mathrm{SnO}_{2}\right)$ relative to a reference system $(\mathrm{Nb}$ $7.5 \mathrm{wt} \% \mathrm{Ta}$ ). SEM images of a fracture surface for (a) the reference sample and (b) with internal oxidation; and (c) the calculated grain size distribution (linear intercept method). Samples were heat treated for $300 \mathrm{~h}$ at $500{ }^{\circ} \mathrm{C}$.

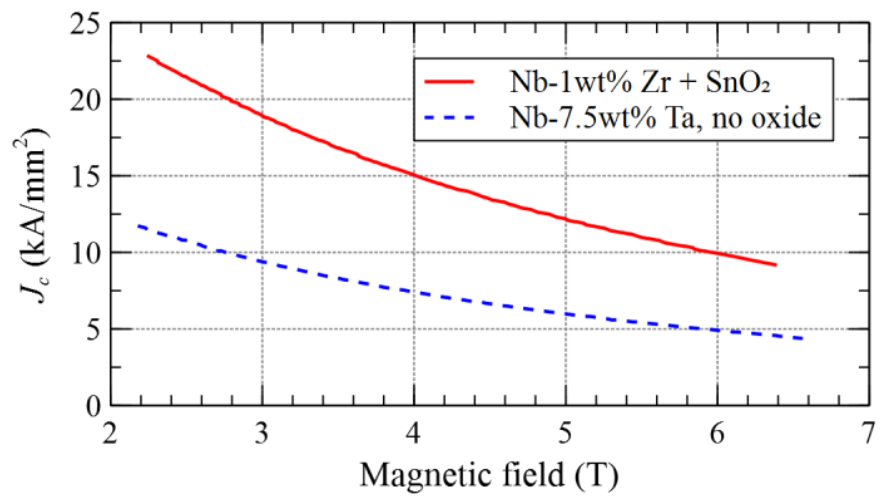

Fig. 12. Inductive $J_{c}(B)$ showing an enhancement in $J_{c}$ for a sample with internal oxidation $\left(\mathrm{Nb}-1 \mathrm{wt} \% \mathrm{Zr}\right.$ with $\left.\mathrm{SnO}_{2}\right)$ relative to a reference system $(\mathrm{Nb}$ $7.5 \mathrm{wt} \% \mathrm{Ta})$. The heat treatment included plateaus at $210{ }^{\circ} \mathrm{C}(50 \mathrm{~h}), 400{ }^{\circ} \mathrm{C}$ $(50 \mathrm{~h}), 500{ }^{\circ} \mathrm{C}(50 \mathrm{~h})$ and $650^{\circ} \mathrm{C}(200 \mathrm{~h}) . J_{c}$ calculated from magnetization at $4.2 \mathrm{~K}$ based on the whole $\mathrm{Nb}_{3} \mathrm{Sn}$ area (coarse and fine grained). mentary model system with an oxide core and external $\mathrm{Cu}-\mathrm{Sn}$.

Early in the study, it was demonstrated that $\mathrm{MoO}_{3}$ is not a suitable oxygen source. For the conventional combination of a $\mathrm{Nb}-1 \mathrm{wt} \% \mathrm{Zr}$ alloy with a $\mathrm{SnO}_{2}$ oxygen source [15], significant grain refinement has been obtained relative to a reference $\mathrm{Nb}-7.5 \mathrm{wt} \%$ Ta system: for the example shown in Fig. 11, the median grain size was reduced from $153 \mathrm{~nm}$ to $88 \mathrm{~nm}$. It has also been demonstrated by inductive measurements that this results in an increase in $J_{c}$ (Fig. 12). Work is in progress with alternative binary and ternary $\mathrm{Nb}$ alloys.

\section{OTHER MATERIALS}

\section{A. $\mathrm{MgB}_{2}$}

Research on $\mathrm{MgB}_{2}$ at CNR-SPIN aims to develop methods to enable production of a cost-effective $\mathrm{MgB}_{2}$ wire for highfield applications. The main goal is to increase $B_{c 2}$ and pinning strength [16]. The present study aims to achieve this in a scalable way by further developing a cost-effective freeze drying synthesis route for boron nano-powder with controlled defects [17][18]. In addition to pure boron nano-powders, samples with carbon doping and nano-aggregate additions are planned.

The freeze drying approach introduces defects homogeneously dispersed in the volume of the B precursor, producing an already doped nano-B by reduction. In comparison with conventional methods, the use of nano-B with dopants and additions would allow those additions to be introduced within $\mathrm{MgB}_{2}$ grains during solid state $\mathrm{MgB}_{2}$ synthesis.

A $60 \mathrm{~g}$ batch of pure nano-B powder has recently been produced and characterized by SEM, EDX analysis and X-ray diffraction (XRD). The morphology, as shown in Fig. 13, suggests a predominantly amorphous powder with a significant proportion of grains $<50 \mathrm{~nm}$ in size, and a size distribution extending up to $140 \mathrm{~nm}$. XRD analysis shows a few lowintensity peaks on a broad background, suggesting the presence of a small proportion of crystalline grains in predominantly amorphous material. The oxygen content determined by EDX is 1.6-1.8 wt\%, comparable to commercial B powders. Production of a multifilamentary prototype wire with this material is planned at Columbus Superconductors.

\section{B. $B S C C O 2212$}

BSCCO 2212 has proven potential to achieve the target $J_{c}$ for the FCC Study in an isotropic round-wire geometry [19].

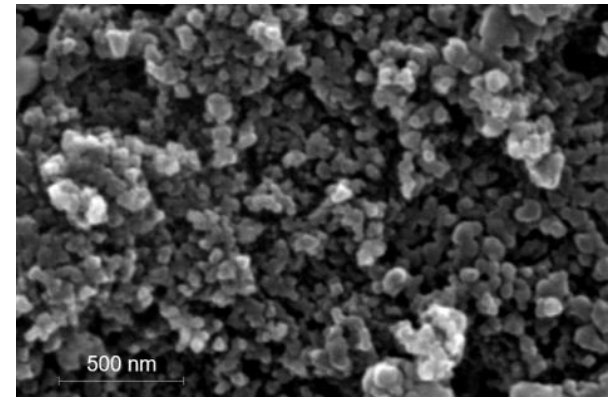

Fig. 13. SEM micrograph of pure nano-boron prepared at CNR-SPIN by a freeze drying process. 
However, this has been achieved through over-pressure processing (50-100 bar), which would be challenging to implement for the manufacture of large magnets. At CNR-SPIN, an alternative groove rolling process is under development [20]. In the present project, the aim is to demonstrate a $J_{e}$ of $500 \mathrm{~A} \mathrm{~mm}^{-2}$ at $16 \mathrm{~T}$ and $4.2 \mathrm{~K}$ through optimization of the wire architecture, deformation processing and heat treatment.

A proper alternation of groove rolling and drawing steps results in greater powder densification than drawing alone, and the resulting reduction in filament porosity inhibits bubble formation during the subsequent heat treatment. In general, the larger the degree of densification (i.e. the larger the proportion of the reduction achieved by rolling), the better the $J_{e}$ performance, even when cracks and disordered filaments are evident in the cross-section (Fig. 14). Further work is required to optimize the groove rolling steps to avoid distortion of the filament bundles, and hence maximize the effective cross-section.

To support heat treatment optimization, the partial melting process has been investigated by in situ $\mathrm{x}$-ray and neutron diffraction [21]. This study clarified the role of oxygen activity in BSCCO 2212 texturing, and clarified the conditions under which undesired secondary phases form. New heat treatment profiles implementing these findings are currently under test.

Recent $I_{c}$ tests on 1-m-long samples have shown almost identical $J_{e}$ results to short samples, suggesting very good longitudinal homogeneity [22]. It is therefore expected that this processing route will be scalable to industrial production.

\section{Iron-based superconductors}

The recently discovered iron-based superconductors [23][24] are at a much less mature state of development, but they have considerable potential for high-field applications: indeed, they are the baseline solution for dipole magnets in the proposed CEPC and SPPC accelerators [25]. CNR-SPIN is seeking to develop two prototype conductors with a $J_{c}$ of

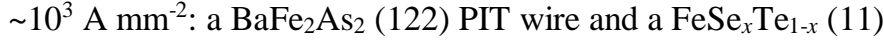
coated conductor $(\mathrm{CC})$.

The 122 PIT activity is currently focused on powder synthesis. The aim of the work was to identify a reproducible and efficient route to synthesize large polycrystalline samples $(\sim 5 \mathrm{~g})$ of $\mathrm{Ba}_{1-x} \mathrm{~K}_{x} \mathrm{Fe}_{2} \mathrm{As}_{2}$ with purity $>96 \mathrm{wt} \%$ (Fig. 15(a)). The optimized route needs three steps: preparation of a FeAs precursor, reaction of $\mathrm{Ba}, \mathrm{K}$ and $\mathrm{FeAs}$, and sintering of the $(\mathrm{Ba}, \mathrm{K}) \mathrm{Fe}_{2} \mathrm{As}_{2}$ pellet. Recently, samples with a $\mathrm{Ba} / \mathrm{K}$ ratio very close to one and a $T_{c}$ of $\sim 38 \mathrm{~K}$ were successfully produced.

The 11 CC activity aims to develop substrates with a simpler, more cost-effective template than the traditional Rolling Assisted Biaxially Textured Substrates (RABiTS) and IonBeam Assisted Deposition (IBAD) routes developed for

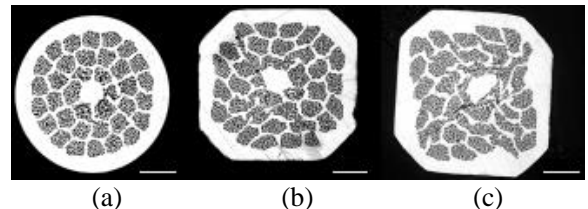

Fig. 14. SEM micrographs of BSCCO 2212 wires with different proportions of the reduction achieved by drawing and groove rolling: (a) drawn, (b) mostly drawn, (c) mostly groove rolled. The scale marker represents $250 \mu \mathrm{m}$.
YBCO. This is feasible because the critical angle at which $J_{c}$ starts to decrease exponentially is about $9^{\circ}$, much larger than for YBCO $\left(\sim 3^{\circ}\right)$, and because 11 thin film deposition is performed at low temperature $\left(300^{\circ} \mathrm{C}\right)$ under high vacuum.

An Invar 36 substrate with strong cube texture and misorientation angles (in and out of plane) of less than $10^{\circ}$ was developed (Fig. 15(b)). Even without a buffer layer, epitaxial 11 thin films were successfully deposited at $200{ }^{\circ} \mathrm{C}$ on a 11 seed layer with misorientation angles of less than $8^{\circ}$. These films were not superconducting because of Ni poisoning revealed by transmission EDX analysis [26]. In parallel, the deposition of 11 films was also performed on $\mathrm{Ni}-5 \mathrm{wt} \% \mathrm{~W}$ substrate with a $50 \mathrm{~nm}$ thick $\mathrm{CeO}_{2}$ buffer layer, supplied by ENEA in Frascati. On this substrate, 11 thin films with a $T_{c}$ of about $18 \mathrm{~K}$ and a $J_{c}$ of $10^{5} \mathrm{~A} / \mathrm{cm}^{2}$ at $4.2 \mathrm{~K}$ in self-field were obtained [27].

$\mathrm{Ni}-5 \mathrm{wt} \% \mathrm{~W}$ with other oxide buffer layers, and Invar 36 substrates with nitride buffer layers, are now under study.

\section{CONCLUSIONS AND FUTURE DiRECTIONS}

In the context of the FCC Study, a Conductor Development Program has been established at CERN to develop a superconducting wire meeting the performance targets: notably, a non-copper critical current density $\left(J_{c}\right)$ of $1500 \mathrm{~A} \mathrm{~mm}^{-2}$ at $16 \mathrm{~T}$ and $4.2 \mathrm{~K}$. Four $\mathrm{Nb}_{3} \mathrm{Sn}$ wire manufacturers are currently participating, three of which have successfully achieved the stage one target $J_{c}$ comparable to the HL-LHC specification, in one case in kilometer piece lengths. Evidence has been presented of the potential for further increases in $J_{c}$, and these development activities will continue for at least two more years.

Achieving the ultimate target $J_{c}$ is likely to require a major innovative step, and this is a growing focus of the program. Investigations of novel alloys and internal oxidation methods are in progress, and will be enhanced by the recent addition of a new research partner (NHMFL, FSU); and two new manufacturers are expected to the join the program in the coming months to develop novel wire layouts. This work is supported by fundamental studies of thermodynamics and detailed analysis of $\mathrm{Nb}_{3} \mathrm{Sn}$ microstructures and pinning.

$\mathrm{Nb}_{3}$ Sn remains the baseline solution, but novel approaches are also being investigated to develop $\mathrm{MgB}_{2}$, BSCCO 2212 and iron-based superconductors for high field applications.

\section{ACKNOWLEDGMENT}

The authors would like to thank A. T. Perez Fontenla and her colleagues in CERN's Metallurgy and Metrology section (EN-MME-MM) for metallography and electron microscopy,
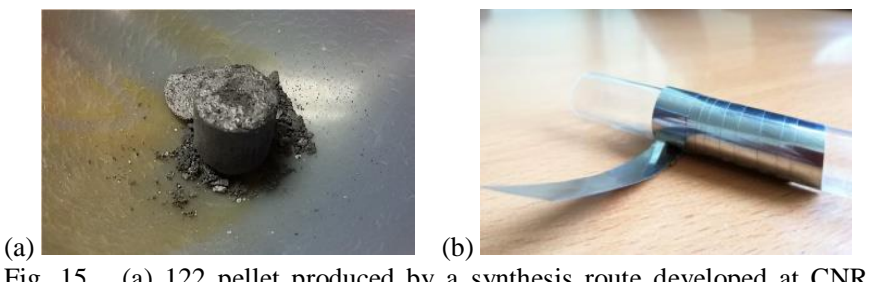

Fig. 15. (a) 122 pellet produced by a synthesis route developed at CNRSPIN. The product is dark grey, dry, crystalline and rather compact, but brittle. (b) Invar 36 substrate, $70 \mu \mathrm{m}$ thick. 
and the technical staff of the Superconductors and Superconducting Devices section (TE-MSC-SCD) for performing heat treatments and electrical measurements.

\section{REFERENCES}

[1] E. Todesco et al., "Progress on HL-LHC $\mathrm{Nb}_{3}$ Sn Magnets", IEEE Trans. Appl. Supercond., vol. 28, no. 4, Jun. 2018, Art. no. 4008809.

[2] A. Ballarino and L. Bottura, "Targets for $\mathrm{R} \& \mathrm{D}$ on $\mathrm{Nb}_{3} \mathrm{Sn}$ Conductor for High Energy Physics", IEEE Trans. Appl. Supercond., vol. 25, no. 3, Jun. 2015, Art. no. 6000906.

[3] A. Ballarino, "Superconductors for Future Circular Colliders", presented at the $24^{\text {th }}$ Int. Conf. Magn. Technol. (MT24), Seoul, Korea, Oct. 21, 2015. [Online]. Available: https://fcc.web.cern.ch/Pages/news/Magnettechnology-conference-features-techniques-for-the-FCC.aspx

[4] B. Bordini, "Magnetization Measurements of High- $J_{c} \mathrm{Nb}_{3} \mathrm{Sn}$ Strands", IEEE Trans. Appl. Supercond., vol. 23, no. 3, Jun. 2013, Art. no. 7100806.

[5] S. C. Hopkins, A. Baskys, A. Canós Valero, and A. Ballarino, "Quantitative Analysis and Optimization of $\mathrm{Nb}_{3} \mathrm{Sn}$ Wire Designs Towards Future Circular Collider Performance Targets", IEEE Trans. Appl. Supercond., submitted for publication.

[6] J. Kim, "Development Status of $\mathrm{Nb}_{3} \mathrm{Sn}$ Strand for $\mathrm{FCC}$ ", presented at FCC Week 2018, Amsterdam, Netherlands, 2018. [Online]. Available: https://indico.cern.ch/event/656491/contributions/2920090/

[7] S. Kawashima et al., "Development of High Current Density Distributed Tin Processed $\mathrm{Nb}_{3}$ Sn Wire", IEEE Trans. Appl. Supercond., submitted for publication.

[8] T. Baumgartner, S. Pfeiffer, J. Bernardi, A. Ballarino, and M. Eisterer, "Effects of inhomogeneities on pinning force scaling in $\mathrm{Nb}_{3} \mathrm{Sn}$ wires," Supercond. Sci. Technol., vol. 31, no. 8, Aug. 2018, Art. no. 084002.

[9] T. Baumgartner, J. Hecher, J. Bernardi, S. Pfeiffer, C. Senatore, and M. Eisterer, "Assessing composition gradients in multifilamentary superconductors by means of magnetometry methods," Supercond. Sci. Technol., vol. 30, no. 1, Jan. 2017, Art. no. 014011.

[10] S. Martin, A. Walnsch, G. Nolze, A. Leineweber, F. Léaux, and C. Scheuerlein, "The crystal structure of $\left(\mathrm{Nb}_{0.75} \mathrm{Cu}_{0.25}\right) \mathrm{Sn}_{2}$ in the $\mathrm{Cu}-\mathrm{Nb}-$ Sn system", Intermetallics, vol. 80, 2017, pp. 16-21.

[11] J. Lachmann, "Konstitution des Nb-Sn-Systems und Phasenumwandlung von Nb-Sn-Phasen unter Beteiligung von Kupfer", Diploma Thesis, TU Bergakademie Freiberg, Freiberg, Germany, 2018.

[12] X. Xu, M. Sumption, X. Peng, and E. W. Collings, "Refinement of $\mathrm{Nb}_{3}$ Sn grain size by the generation of $\mathrm{ZrO}_{2}$ precipitates in $\mathrm{Nb}_{3}$ Sn wires", Appl. Phys. Lett., vol. 104, no. 8, Feb. 2014, Art. No. 082602.

[13] L. E. Rumaner, M. G. Benz, and E. L. Hall, "The role of oxygen and zirconium in the formation and growth of $\mathrm{Nb}_{3} \mathrm{Sn}$ grains", Met. Mater. Trans. A, vol. 25, no. 1, 1994, pp. 213-219.

[14] B. A. Zeitlin et al., "Results on Mono Element Internal $\mathrm{Tin} \mathrm{Nb}_{3} \mathrm{Sn}$ Conductors (MEIT) With $\mathrm{Nb} 7.5 \mathrm{Ta}$ and $\mathrm{Nb}\left(1 \mathrm{Zr}+\mathrm{O}_{\mathrm{x}}\right)$ Filaments", IEEE Trans. Appl. Supercond., vol. 15, no. 2, 2005, pp. 3393-3398.

[15] F. Buta, L. Gamperle, C. Barth, J. Ferradas, and C. Senatore, "Towards a $\mathrm{Nb}_{3} \mathrm{Sn}$ conductor for FCC", presented at FCC Week 2018, Amsterdam, Netherlands, 2018.2 [Online]. Available: https://indico.cern.ch/event/656491/contributions/2919973/

[16] M. Putti and G. Grasso, " $\mathrm{MgB}_{2}$, a two-gap superconductor for practical applications", MRS Bull., vol. 36, no. 8, Aug. 2011, pp. 608-613.

[17] M. Vignolo et al., "A Novel Process to Produce Amorphous Nanosized Boron Useful for $\mathrm{MgB}_{2}$ Synthesis", IEEE Trans. Appl. Supercond., vol. 22, no. 4, 2012, Art. no. 6200606.

[18] M. Vignolo et al, "Nano-sized boron synthesis process towards the large scale production", Chem. Eng. J., vol. 256, Nov. 2014, pp. 32-38.

[19] D. C. Larbalestier et al., "Isotropic round-wire multifilament cuprate superconductor for generation of magnetic fields above 30 T", Nature Mater., vol. 13, no. 4, Mar. 2014, pp. 375-381.

[20] A. Leveratto, V. Braccini, D. Contarino, C. Ferdeghini, and A. Malagoli, "New concept for the development of Bi-2212 wires for high-field applications", Supercond. Sci. Technol., vol. 29, no. 4, 2016, Art. No. 045005.

[21] A. Martinelli et al., "In situ x-ray and neutron diffraction investigation of Bi-2212 in multifilamentary wires during thermal treatment", Phys. Rev. Mater., vol. 2, Aug. 2018, Art. no. 084801.
[22] L. Leoncino et al., "Evidence for Longitudinal Homogeneity and No $J_{e}$ Degradation in Bi-2212 Wires Realized by the GDG Process", IEEE Trans. Appl. Supercond., submitted for publication.

[23] Y. Kamihara, "Iron-Based Layered Superconductor: LaOFeP", J. Am. Chem. Soc., vol. 128, no. 31, 2006, pp. 10012-10013.

[24] Y. Kamihara, T. Watanabe, M. Hirano, and H. Hosono, "Iron-Based Layered Superconductor $\mathrm{La}\left[\mathrm{O}_{1-x} \mathrm{~F}_{x}\right] \mathrm{FeAs} \quad(x=0.05-0.12) \quad$ with $T_{c}=26$ K", J. Am. Chem. Soc., vol. 130, no. 11, 2008, pp. 3296-3297.

[25] CEPC Study Group, CEPC Conceptual Design Report: Volume I-Accelerator, Aug. 2018, Institute of High Energy Physics (IHEP). [Online]. Available: http://cepc.ihep.ac.cn/CDR_v6_201808.pdf

[26] G. Sylva et al., "Analysis of $\mathrm{Fe}(\mathrm{Se}, \mathrm{Te})$ Films Deposited on Unbuffered Invar 36", IEEE Trans. Appl. Supercond., submitted for publication.

[27] V. Braccini et al., Supercond. Sci. Technol., submitted for publication. 